\title{
Commentary
}

\section{Using a community engagement program to promote veterinary medicine while helping veterinary students improve their communication skills and increase their cultural understanding and well-being}

\author{
Lindley McDavid PhD \\ Sandra F. San Miguel DVM, PhD
}

\author{
From the Evaluation and Learning Research Center (McDavid) and Departments of \\ Veterinary Administration and Veterinary Clinical Sciences, College of Veterinary \\ Medicine (San Miguel), Purdue University, West Lafayette, IN 47907. \\ Address correspondence to Dr. San Miguel (amasss@purdue.edu).
}

$\mathbf{T}$ he AAVMC Foresight report ${ }^{1}$ identified community engagement as a means of promoting the societal value of veterinary medicine, garnering public trust, and educating young people about the role of veterinarians. Through community engagement, veterinary professionals can build relationships that create opportunities for community members to better trust and comply with medical recommendations to increase patient well-being. ${ }^{2,3}$ In addition, veterinary students may derive particular benefits from community-engagement opportunities. However, there is a dearth of research examining veterinary student community-engagement and service-learning experiences beyond the development of clinical skills. ${ }^{4}$

Community-engagement experiences for veterinary students can increase the visibility and status of the profession and educate the public on the links between animal and public health. Veterinary students can also use these experiences to develop core professional competencies. Alongside faculty mentors, veterinary students can leverage their interactions with community members of diverse backgrounds and ages to develop professional skills in communication, equity-mindedness, inclusivity, cultural competency, and more. ${ }^{2,3,5}$ Further, the development of communication skills is identified in the AAVMC CompetencyBased Veterinary Education Framework ${ }^{5}$ as essential for safeguarding both animal and public health. Findings in human medicine indicate positive associations between improvements in communication practices and favorable patient outcomes. ${ }^{6}$ To yield similar benefits, veterinary students require consistent and targeted practice that extends beyond single or shortterm lessons. ${ }^{7-10}$ Veterinary colleges use a variety of methods to focus on these skills through coursework, role playing, guest speakers, and community-service programs..$^{7-10}$ However, students need opportunities to interact with and adapt their communication styles to a range of conversational partners, such as clients

\footnotetext{
ABBREVIATIONS

AAVMC American Association of Veterinary Medical Colleges
}

and colleagues. ${ }^{11}$ For veterinary medical students, practicing their communication skills during community engagement could provide such opportunities and expedite their growth, in that these nontechnical competencies might be more effectively developed in contexts of immediate application. ${ }^{12}$ Even more, Gaida et $\mathrm{a}^{11}$ suggested that confidence in communication skills supports veterinarians' mental health as well.

As part of its efforts to expose underserved children to the veterinary profession, the Purdue University College of Veterinary Medicine has developed a network of formal partnerships among veterinary colleges and community entities to deliver programs to increase the interest in careers in science, technology, engineering, and math. In particular, the This Is How We "Role" program was developed to be a sustainable, culturally responsive program that would expose elementary school students diverse in gender, race, and ethnicity to low-cost, fun, educationally engaging lessons that would foster interest in science, technology, engineering, and math careers. ${ }^{13}$

The This Is How We "Role" lessons were designed to be delivered by faculty veterinarians and veterinary medical students acting as role models. The children's level of engagement with the lessons has been studied $^{13}$; however, the role models' perceptions of the benefits they received as a result of participating in the program have not been formally studied. Recently, preliminary focus group sessions were held to begin to identify specific benefits of volunteering as a role model for the This Is How We "Role" program.

\section{Focus Group Findings}

Focus group sessions were held with 10 Purdue University veterinary medical students who had volunteered as role models for the This Is How We "Role" program. There were 8 women and 2 men ranging in age from 23 to 30 years old. Participants consisted of 6 white students, 2 Latino students, and 2 Black students. A formal analysis of the focus group findings was not performed. Still, 4 dominant themes emerged during the conversations. 


\section{Promoting veterinary careers}

The AAVMC Foresight Report specifically recommends mentoring as an important method for educating youth about veterinary medicine. ${ }^{1}$ Role models reiterated this perspective and communicated the importance of having afterschool programs that offer curricula beyond standard school offerings to introduce young people to the field while providing interesting and fun academic content. The role models saw their involvement as essential in this process and shared that they would have appreciated the opportunity to be exposed to similar skill- and mentoringfocused programming as young children. As one of the focus group participants indicated, "Vet medicine seems like such a far-off goal until you've met someone [who is] there or is getting there. Just showing the kids [that] we are real people and ... giving them an actual picture instead of this word 'veterinarian,' which seems so far off and un-relatable."

Although the focus of the program was delivery of a science-based curriculum, role models shared that the program provided opportunities to help with the everyday challenges and realities of the young children participating in the program. Role models helped children with other academic work, home life, self-esteem, and more. We believe that this mentorship could have a substantial impact on the lives of these children, because mentorship from caring adults is essential to support skill building and career awareness in young people in afterschool programs. ${ }^{14,15}$ As one of the participants said, "We don't just help them with vet school. [We help with] math, hair, and general life questions. Just being there to be a positive influence on someone's life is really constructive." Another participant noted that, "We did multiplication tables with a young girl after she said 'I love math! Give me some math problems!' It was great to encourage her."

Veterinary students who participated in the program for more than one semester appreciated seeing children develop and nurture their personal potential over time. "Watching a student grow as an individual and watching him really develop academically over the past years [is rewarding]. The kid stands out in the crowd and he will likely become a scientist."

\section{Cultural understanding}

Role models also appreciated interacting with people from backgrounds different than their own and shared that these interactions helped shed some misconceptions about underserved youth. One participant related a story of a child who asked why the role model's skin turned white when pressed, since the child's skin didn't do that. "It was so hard for me, because I didn't know what to say. And she approached it so innocently. And I talked about capillary refill, and it was a cool experience to explain something without delving into [the complexities of race]." Another participant noticed that some of the Spanish-speaking children were reluctant to speak during the lessons and wondered "Is there something going on there? I wonder what is happening there and how we can help them."

\section{Communication}

Role models discussed that the program afforded opportunities to gain confidence speaking as an expert while applying their veterinary science knowledge. One role model admitted previously not liking talking to crowds or a classroom, saying that, "I was scared in the first lesson but now I have fun with it. And it frees me up to be more comfortable speaking." Another related, realizing that, "veterinarians ... are more like teachers to our clients. Because we have to educate them, that is a big responsibility. Doing this helps remind me that we can teach others and working with kids is a good way to practice that."

Role models shared how discussing veterinary science with children would help them teach future clients about the health of their animals and be more comfortable with inevitable difficult client conversations in the near future. "[I learned] how to simplify information; it is harder than you think sometimes. ... As a veterinarian you are going to have to do that for the rest of your life. If the client doesn't understand you, they won't do it. So, you have to be able to communicate well to all audiences." Another role model related that, "Sometimes kids would tell me about their dog who died. This is good practice of how to talk to future clients about harder situations but in a less stressful context for now."

\section{Well-being}

Similar to human medical students, veterinary medical students struggle with work-life balance, anxiety, and stress. ${ }^{16}$ Veterinary medical programs are rigorous, challenging, and time intensive, and new commitments may be overwhelming. Although some role models initially thought participation in the This Is How We "Role" program might add additional stress, many commented that the program became a needed relief and an opportunity to reflect and recommit to their studies and future profession. As one suggested, "[One benefit is] learn[ing] what you know and don't know and being okay with that. Being okay with not knowing everything." Another noted that questions from the students about why they went to veterinary school "helped make me think about that. Not that I'm here but why and how."

Just as community engagement opportunities can help develop the whole student, as described by Stukas et al, ${ }^{17}$ the This Is How We "Role" program helped role models monitor, gain control of, and cope with their academic stress by helping them feel connected to the community, giving them opportunities to reflect on their journey, and enabling them to commit to something good beyond their studies. "Going somewhere that is not [the classroom] reminds [us] that there is a whole rest of the world out there and don't get too wrapped up in vet school and forget 
about everything else that has meaning and value." As one role model put it, "Learning about why you should reach out to the community gives me a better idea of why community is important and why you should try to contribute to it."

\section{Conclusions}

To date, we have collected comments from only a subset of veterinary students who participated in the This Is How We "Role" program. Importantly, the program was designed to meet learning objectives and academic standards for participating community children; however, it clearly also included elements that support veterinary student academic and personal growth. The comments we have received suggest that veterinary medical student community-engagement and servicelearning experiences focused on clinical skill or pipeline development can be intentionally leveraged to add learning objectives that address competencies listed in the AAVMC's Competency-Based Veterinary Education Framework domains of communication, collaboration, and professionalism and professional identity. In summary, community-engagement experiences are opportunities for veterinary students to cultivate professional skills, cope with stress, and impact communities, while increasing the visibility and positive impact of the veterinary profession.

\section{Acknowledgments}

The This Is How We "Role" program is supported by the Science Education Partnership Award program of the National Institute of General Medical Sciences of the National Institutes of Health. Its contents are solely the responsibility of the authors and do not necessarily represent the official views of the National Institutes of Health.

\section{References}

1. Willis NG, Monroe FA, Potworowski JA, et al. Envisioning the future of veterinary medical education: the Association of American Veterinary Medical Colleges Foresight Project, final report. J Vet Med Educ 2007;34:1-41.

2. Burge GD. Six barriers to veterinary career success. $J$ Vet Med Educ 2003;30:1-4.
3. Hughes K, Rhind SM, Mossop L, et al. "Care about my animal, know your stuff and take me seriously"; United Kingdom and Australian client's views on the capabilities most important in their veterinarians. Vet Rec 2018;183:534-542.

4. Freeman LJ, Ferguson N, Litster A, et al. Service learning: Priority 4 Paws mobile surgical service for shelter animals. $J$ Vet Med Educ 2013;40:389-396.

5. AAVMC Working Group on Competency-Based Veterinary Education, Molgaard LK, Hodgson JL, et al. Competencybased veterinary education: part 1-CBVE framework. Washington, DC: Association of American Veterinary Medical Colleges, 2018;1-17.

6. Shaw JR, Adams CL, Bonnett BN. What can veterinarians learn from studies of physician-patient communication about veterinarian-client-patient communication? J Am Vet Med Assoc 2004;224:676-684.

7. Adams CL, Conlon PD, Long KC. Professional and veterinary competencies: addressing human relations and the human animal bond in veterinary medicine. J Vet Med Educ 2004;31:66-71.

8. Burns GA, Ruby KL, DeBowes RM, et al. Teaching non-technical (professional) competence in a veterinary school curriculum. J Vet Med Educ 2006;33:301-308.

9. Butler C, Williams S, Koll S. Perceptions of fourth-year veterinary students regarding emotional support of clients in veterinary practice in the veterinary college curriculum. $J$ Am Vet Med Assoc 2002;221:360-363.

10. Shaw JR, Barley GE, Hill AE, et al. Communication skills education onsite in a veterinary practice. Patient Educ Couns 2010;80:337-344.

11. Gaida S, Härtl A, Tipold A, et al. Communication identity in veterinary medicine: a grounded theory approach. Vet Rec Open 2018;5:e000310.

12. Lloyd JW, Walsh DA. Template for a recommended curriculum in "veterinary professional development and career success." J Vet Med Educ 2002;29:84-93.

13. San Miguel SF, McDavid L, Parker L, et al. Developing a scalable STEM career development program for elementary school-aged students. J STEM Outreach 2019;2:1-10.

14. Damon W. What is positive youth development? Ann Am Acad Pol Soc Sci 2004;591:13-24.

15. Eccles J. Gendered educational and occupational choices: applying the Eccles et al model of achievement-related choices. Int J Behav Dev 2011;35:195-201.

16. Strand EB, Zaparanick TL, Brace JJ. Quality of life and stress factors for veterinary students. J Vet Med Educ 2005;32:182192.

17. Stukas AA Jr, Clary G, Snyder M. Service learning: who benefits and why. Soc Res Child Dev 1999;13:1-20.

For all commentaries, views expressed are those of the authors and do not necessarily reflect the official policy of the AVMA. 